\section{PSYCHIATRIC TREATMENT OF} ALCOHOLISM

DeAR Sir,

I do not wish to suggest that the article by $\mathrm{Dr}$ Davies on alcoholism (Journal, May 1979, 134, 44958 ) is any worse than many other papers that our system allows publication. If I choose it for attack, it is not because of the author (of whom I had never heard previously), but perhaps because one just has to protest sometimes, or because we have just recently buried an alcoholic friend here-Ruthven Todd, one-time writer and artist and crony of Dylan Thomas . . . or because I think of the late genius of Irish music, Sean O'Riada . . . and of how the problem of the artist and alcoholism has never received the attention it demands.

It is difficult to believe that this article is a "Revised Version". In fact, it may be a help in teaching as an example of "How Not to Do It"; and I shall probably use it thus. Its most striking quality is its superficiality in all aspects of the problem dealt with. Alcoholism is, after all, primarily a psychological problem (pace psychiatrists, sociologists and others!): yet there is no reference to the vast psychological literature of relevance here. Even more fundamentally, with regard to the way we talk and hence think about the problem, there is no awareness of the necessity of linguistic analysis, of the crying need for operational definitions of such key concepts as 'illness' and 'alcoholism' or of the basic question as to just how many and which disorders traditionally dealt with by psychiatrists are 'illnesses', anyway.

A psychologist stares in disbelief at the repeated, unanalysed, uncritical use of the meaningless, archaic terms, 'strength of character' and 'will-power'. (May I refer here to my own article, 'The Concept of Responsibility', Journal, 1955, which was the major influence apparent in the British Psychological Society's Memorandum of Evidence to the Butler Committee on the Law Relating to the Mentally Abnormal Offender twenty years later). By "psychiatrists may operate with predominantly static models of motivation" the author means simply that some psychiatrists do not think they can or should alter patients' motivations. (Then what are they in business for, asks a small voice?). The ethical questions of patients' motivations and of modifying them are conscientiously ignored.

The strongest impression conveyed is that psychiatrists haven't got a clue as to what alcoholism really is or as to what (if anything) they should do about it; and that the harassed doctors quoted, like the sociologist himself, are struggling with something out of their field-and depth-on a level with the priest or 'meenister', unsullied by any course in con- temporary psychology. It may serve a useful purpose in showing those commanding the heights, whether of Hampstead or Denmark Hill, just what goes on at grass-roots level. At any rate, it makes a psychologist realise how much superior and more useful a behavioural formulation, involving a systematic functional analysis of behaviour, is.

Making heavy weather of what little he has to say, the author shows the long-windedness, repetitiveness, inexact and over-general use of terms, tautologies and discovery of the obvious which unfortunately characterize the American-sociologese style, complete with 'Figures' (sic) and quintuple columns of symbols, meaningless in the present context, adding a spurious mathematical-scientific gloss to the shoddy paper.

The psychologist's dismay mounts on reading that more of the same is on the way-research not into the nature, causes and treatments of alcoholism (nothing so simple-minded and straightforward) but to determine "the nature and direction [?] of patients' expectations of alcoholism treatment". What I object to, and what I think society should object to, is allocation from paltry research funds to such piffling-and, worse, confusing-pseudo-academic exercises. Partly the fault lies in the wrong people trying to do the wrong things: here, it is crucial that physician, psychiatrist, psychologist, sociologist and others concerned sort out where their respective knowledge and skills, and hence their respective potential contributions, lie. This is surely a prerequisite to any inter-disciplinary research. A major weakness of sociologists in work like that under review, and of those psychologists who have taken a Ph.D. but no Clinical Course, is their lack of primary clinical experience and responsibility prior to plunging into clinical research-or, more accurately in their case, research in the field of abnormal behaviour. We can trace the fault back to their teachers, of course ... and to their teachers ... and to those deciding who gets the research grants ... and to their teachers ... It's not the parents' fault, either ...?

Ca'n Sitin, Galilea,

J. Edwin Macdonald

Mallorca, Spain

Dear Sir,

Thank you for giving me an opportunity to respond to Dr J. Edwin Macdonald's comments on my article published in the May issue of the Journal.

Of the number of issues raised by Dr Macdonald I do not think that the correspondence column of this Journal is the appropriate place to discuss the allocation of research funds in the medical, social and 
behavioural sciences. Nor is it the place to engage in idle speculation about my own or anyone else's personal or intellectual parentage. I also think that one should make due allowance for the fact that Dr Macdonald has recently buried an alcoholic friend, a life event which may well have disturbed Dr Macdonald's affective neutrality and scientific objectivity with respect to the matters at hand.

I would like to use this column, however, to respond to some of $\mathrm{Dr}$ Macdonald's more principled objections to my article. First of all I do think that Dr Macdonald is being somewhat narrow-minded, if not presumptuous, by declaring alcoholism to be "primarily a psychological problem". It is my impression that alcohological thinking and practice has come some way from undimensional conceptions of alcoholism and that it is now customary to locate the causes, dynamics and outcomes of alcoholism within the complex interactions between psychological, social, environmental and economic factors. However, even if alcoholism is primarily a psychological problem the question remains as to how, and which, psychological processes are attributed to the sorts of problems that people bring to alcoholism clinics. It is this question, inter alia, which is of interest to the sociologist and which I tried to address in my article. Whilst it is undoubtedly the case that $I$ have not given due reference to "the vast psychological literature" mentioned by Dr Macdonald, this was in keeping with Dr Macdonald's principle whereby "the physician, psychiatrist, psychologist, sociologist and others concerned sort out where their respective knowledge and skills, and hence their respective potential contributions, lie".

Dr Macdonald, however, has some more fundamental objections to my paper. In particular, he feels that there is no awareness of the necessity of linguistic analysis, of the crying need for operational definitions of such key concepts as 'illness' and 'alcoholism' or of the basic question as to just how many and which disorders traditionally dealt with by psychiatrists are 'illnesses' anyway. It would appear that Dr Macdonald and myself have opposing conceptions of linguistic analysis. For my part I would argue that the meanings of lexical items such as 'illness' and 'alcoholism' are derived not from some de-contextualized principle of classification (langue) but from their usage in everyday discourse (parole). Not only do I have an acute awareness of the necessity of linguistic analysis in the study of alcoholism (albeit different to that of Dr Macdonald) but I would also suggest that my article in the May issue of the Journal was a first step in this direction. After all, the article is about the ways psychiatrists and patients talk to each other about alcohol-related conditions and problems and in so doing negotiate the rights and responsibilities associated with those problems and conditions. So far as whether or not the conditions and disorders dealt with by psychiatrists are 'illnesses' anyway, this will hardly be settled simply by invoking de-contextualized operational definitions. With respect to alcoholrelated conditions, no matter how precisely one may define 'illness' or 'alcoholism', there will still be patients like K.S. in my article who both expect to have their alcohol-related problem treated like a physical ailment or condition and who will engage in all sorts of speech exchanges with doctors and psychiatrists to claim their right to this.

This brings me to another of Dr Macdonald's objections to my article, namely the "repeated, unanalysed, uncritical use of the meaningless archaic terms 'strength of character' and 'will-power'." I hasten to point out that these terms were generated not by myself but by the authors of the health education literature to which I refer at the outset of my article, and by the psychiatrists in the clinics under observation. If it is the case that these terms are repeated in my article, this is because they are repeated by the psychiatrists in the context of alcoholism consultations. I am not sure what sort of analysis Dr Macdonald would like to have seen, but I do not agree that these terms are left unanalysed by myself. My analysis of these terms is one in which I examine the ways in which they are used in alcoholism consultations and the sorts of work that they do when they are used. In particular, I offer an analysis of the ways in which terms such as 'willpower' and 'strength of character' serve to allocate responsibility to alcoholism patients for their condition and its treatment. I do not see it as part of my analysis of these terms to be critical, or otherwise pass judgement on their use. An analysis of their use, does suggest that these terms are far from meaningless. However, I would not expect Dr Macdonald to appreciate that a great deal of meaning may be associated with the use of these terms, given his preference for operational definitions which are totally divorced from linguistic usage.

Finally, if my article has created the impression "that psychiatrists haven't got a clue as to what alcoholism really is or as to what they should do about it" I would like to correct this. My conclusions in the article indicate that it is my impression that psychiatrists have fairly firm ideas as to what alcoholism really is and what they should do about it. Whether one agrees with them or not, psychiatrists display a belief that alcoholism is a matter of willpower, strength of character and self-responsibility, and that what they should do about it consists of 'non-specific elements' such as helping patients to 
gain insight into their lives, situations and conditions. This, I would argue, involves allocating responsibility for the condition to the patient and may not resemble the treatments of physical medicine. The reader will note that this conclusion is congruent with that of other students of alcoholism, such as Orford and Edwards (quoted on page 452 of my article), whose "primary clinical experience and responsibility prior to plunging into clinical research" can certainly not be doubted. However, given that such corroborative evidence has emanated from "those commanding the heights (of) Denmark Hill" I fear that Dr Macdonald will remain unconvinced.

MRC Medical Sociology Unit,

Phil Davies

Institute of Medical Sociology,

Westburn Road, Aberdeen

\section{VALIDITY AND USES OF THE GHQ}

Dear Sir,

In your May issue, Tarnopolsky et al report (Journal, May 1979, 134, 508-15) on the validity of the GHQ in a community sample. They find lower validity than has been reported in samples of general practitioner patients. This finding might be the result of a feature of their research design. The type of illness measured by the GHQ is often quite fleeting. Thus it has been reported that the correlation between GHQ score and total score on the Present State Examination is .8 when the PSE is conducted within a week of the GHQ, but drops below .5 for a longer interval (Duncan-Jones and Henderson, 1978, p. 235). It is clear there was an interval between the GHQ and the validatory psychiatric interview in Tarnopolsky's study, but the length of that interval is not indicated. Since a matching design was used, the interval cannot have been trivial. There was no such interval in the general practitioner studies. Therefore this difference in design might account for the lower validity.

In presenting their data on screening, Tarnopolsky et al make the important point that their data for approximately equal numbers of high scorers and matched low scorers give biased estimates of 'sensitivity' and 'specificity' for the community population, and correct for this by weighting up the low scorers. This would be valid and appropriate if their low scorers were a representative sub-sample of all the low scorers in their original sample. But since they were elaborately matched to the high scorer group, this cannot be so.

It seems possible that the use of matching has weakened this study in two ways. It is feasible to pre-allocate respondents to different sub-sampling classes (prior to first interview) so that (a) subjects for the second phase interview are selected randomly but with probability of selection being dependent on GHQ score, and (b) the first-phase interviewer can determine whether or not a second-phase interview is required, and make a tentative appointment for it. Using this procedure, one can keep the interval between interviews short, and make valid estimates for the whole population from the second phase interview. Details are given in Henderson et al (in press).

Social Psychiatry Research Unit, The Australian National University, Canberra, ACT 2600

\section{References}

Duncan-Jones, P. \& Henderson, S. (1978) The use of a two-phase design in a prevalence survey. Social Psychiatry, 13, 231-7.

Henderson, S., Duncan-Jones, P., Byrne, D. G., ScotT, R. \& ADcock, S. (in press) Psychiatric disorder in Canberra; a standardized study of prevalence. Acta Psychiatrica Scandinavica.

\section{TARDIVE DYSKINESIA AND DEPOT FLUPHENAZINE}

DEAR SIR,

I read with interest Dr Nasrallah's letter (Journal, May 1979, 134, 550) in which he suggested that tardive dyskinesia in patients maintained on depot fluphenazine could be caused by irregular release of fluphenazine from the intramuscular depot. In an earlier study (Nasrallah et al, 1978) he and his colleagues had found wide fluctuations in plasma fluphenazine concentrations in 10 patients during 2 weeks following a $50 \mathrm{mg}$ injection of fluphenazine decanoate: varying numbers of fluphenazine peaks occurred at random, separated by periods in which little or no drug could be detected. (Their analytical procedure, gas-liquid chromatography, could measure fluphenazine concentrations above $3 \mathrm{ng} / \mathrm{ml}$ ). $\mathrm{Dr}$ Nasrallah went on to propose that during depot fluphenazine treatment the decline in plasma fluphenazine levels which followed intermittent peaks could act like a drug withdrawal to cause dyskinesia by producing dopaminergic, receptor hypersensitivity.

We have also examined plasma fluphenazine levels in patients receiving fluphenazine decanoate (Wiles and Gelder, 1979). We used a different analytical technique, a radioimmunoassay, which can measure down to $0.05 \mathrm{ng} / \mathrm{ml}$ (Wiles and Franklin, 1978). In our study, 33 subjects were receiving chronic treatment with a wide range of doses (12.5 to $150 \mathrm{mg}$ ) given at intervals of $1-5$ weeks. Our results differ 